Formation of porous layers on $\mathrm{n}-\mathrm{GaSb}$ by electrochemical etching

This article has been downloaded from IOPscience. Please scroll down to see the full text article.

2004 Semicond. Sci. Technol. 19902

(http://iopscience.iop.org/0268-1242/19/7/021)

View the table of contents for this issue, or go to the journal homepage for more

Download details:

IP Address: 147.96.14.16

The article was downloaded on 21/02/2013 at 13:19

Please note that terms and conditions apply. 


\title{
Formation of porous layers on n-GaSb by electrochemical etching
}

\author{
S Borini ${ }^{1}$, B Méndez ${ }^{2}$ and J Piqueras ${ }^{2}$ \\ ${ }^{1}$ Istituto Elettrotecnico Nazionale 'Galileo Ferraris', Strada della Cacce, 91, I-10135, Torino, \\ Italy \\ ${ }^{2}$ Departamento de Física de Materiales, Facultad de Ciencias Físicas, \\ Universidad Complutense de Madrid, 28040 Madrid, Spain \\ E-mail: bianchi@fis.ucm.es
}

Received 9 February 2004

Published 1 June 2004

Online at stacks.iop.org/SST/19/902

doi:10.1088/0268-1242/19/7/021

\begin{abstract}
The effect of electrochemical etching of n-type GaSb in aqueous solutions of $\mathrm{HCl}$ and $\mathrm{HF}$ has been analysed. By anodization in $\mathrm{HCl}$, two different morphologies of porous layers were observed depending on the current density. At low current density $\left(0.5 \mathrm{~mA} \mathrm{~cm}^{-2}\right)$ a macroporous layer is formed with the pores following preferential directions, while at high current density $\left(15 \mathrm{~mA} \mathrm{~cm}^{-2}\right)$ pores of sizes less than $100 \mathrm{~nm}$ were observed. Furthermore, a comparison between the luminescence in the porous layer and bulk GaSb is also performed. On the other hand, anodization in HF leads to an electropolishing process and no porosification is obtained.
\end{abstract}

\section{Introduction}

Interest in porous semiconductors has been continuously growing since the discovery of luminescent microporous silicon in 1990 [1] and of its possible applications in a variety of fields, such as optoelectronics, sensing and photonics. Most of the previous work has been focused on the study of porous silicon properties (for a review see, e.g., [2]) while the investigation of other porous semiconductors is still at an early stage, and preliminary results are indicating it as a very promising research field.

In particular, III-V semiconductors have shown a number of new interesting properties, such as modification of the luminescent features and formation of various pore morphologies, when electrochemical etching is performed (see [3] for a review). The formation of pores in GaAs [4-6], GaP [7-9], GaN [10, 11], InP [12-15] and InSb [16] has been reported in the literature, and possible applications in optoelectronics and photonics have been proposed. GaSb is a narrow bandgap semiconductor, which is being intensively studied because of its direct gap at around $0.8 \mathrm{eV}$ and its consequent application for the realization of optoelectronic devices and thermophotovoltaic generators. For this reason, the possibility of modifying the bulk material properties by structuring the GaSb surface, in an easy and cheap way such as electrochemical etching, could open an interesting route to the upgrade of GaSb applications. To study the properties of anodized $\mathrm{GaSb}$ we used cathodoluminescence (CL) in a scanning electron microscope. This technique enables us to obtain information about structural, morphological and luminescence features with high spatial resolution and it has been previously used to study porous silicon [17-19].

In a previous report on porous $\mathrm{n}-\mathrm{GaSb}$ [20] the byproducts on the surface of porous $\mathrm{GaSb}$ obtained by electrochemical etching in $\mathrm{H}_{3} \mathrm{PO}_{4}$ solution were studied by Raman scattering, but the porous layers morphology was not investigated. Furthermore, Sabataityté et al [21] have recently reported about pore formation on p-type GaSb by anodization in HF solution.

In this paper, we describe the effect of electrochemical etching on n-type GaSb, showing that pores with two different morphologies can be formed and that the cathodoluminescence emission of the material is strongly affected by the etching process.

\section{Experimental method}

For our experiments, n-type GaSb:Te (100) single-crystal wafers obtained by LEC technique with a thickness of $500 \mu \mathrm{m}$ were used. The anodization process was performed in a Teflon electrochemical single-cell. The back side of the sample was in contact with a steel plate, while an area of $1 \mathrm{~cm}^{2}$ of the 


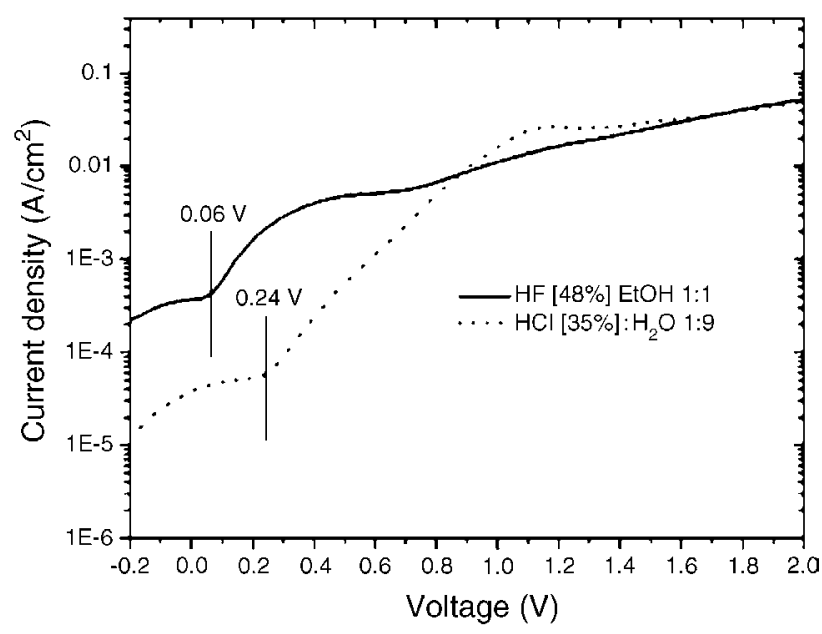

Figure 1. Polarization curves of $\mathrm{n}-\mathrm{GaSb}$ in $\mathrm{HF}$ and $\mathrm{HCl}$ electrolytes, in the dark.

front side was exposed to the electrolyte through a circular hole in the Teflon cell surrounded by an O-ring. A Pt wire was used as counter electrode, and anodizations were carried out by means of a Keithley 2400 generator controlled by a PC with home-made software. Two types of solutions were used: $\mathrm{HF}(48 \mathrm{wt} \%) / \mathrm{EtOH} 1: 1$, and $\mathrm{HCl}(35 \mathrm{wt} \%) / \mathrm{H}_{2} \mathrm{O} 1: 9$. All the experiments were performed in the dark.

After the electrochemical etching, the samples were investigated by scanning electron microscopy (SEM) using a Hitachi S-2500 or a Leica 440 microscope. The CL measurements were carried out in the near infrared range with a cooled ADC germanium detector, at a temperature of $90 \mathrm{~K}$ and an energy of $18 \mathrm{keV}$. X-ray microanalysis was performed in a Jeol JXA-8900 M superprobe.

\section{Results and discussion}

Figure 1 shows the current density versus voltage curves acquired at a scan rate of $0.01 \mathrm{~V} \mathrm{~s}^{-1}$ in $\mathrm{HF}$ and $\mathrm{HCl}$ solutions. In both cases, it can be noted that a steep current increase takes place at a given voltage value (around $0.06 \mathrm{~V}$ for $\mathrm{HF}$ electrolyte, and $0.24 \mathrm{~V}$ for $\mathrm{HCl}$ electrolyte). In previous works on anodization of III-V semiconductors $[6,15,16]$ similar I-V curves have been reported, and the voltage value corresponding to the fast current increase has been defined as the pore formation potential (PFP), i.e. the potential at which electrochemical dissolution of the material begins. This behaviour can be explained considering the Schottky barrier breakdown as the phenomenon responsible for current flow and consequent pore formation. In fact, the porosification needs holes in the material, and when an n-type semiconductor is anodically biased, depletion of majority carriers and formation of a Schottky barrier take place at the semiconductor/electrolyte interface until breakdown occurs and electrochemical dissolution starts. In our case, the PFP seems to be located at $0.06 \mathrm{~V}$ and $0.24 \mathrm{~V}$ for the two different electrolytes. However, as we did not use any reference electrode, the $\mathrm{I}-\mathrm{V}$ measurements are qualitative and indicate that electro-dissolution takes place with the same mechanism already observed in the case of other IIIV compounds.

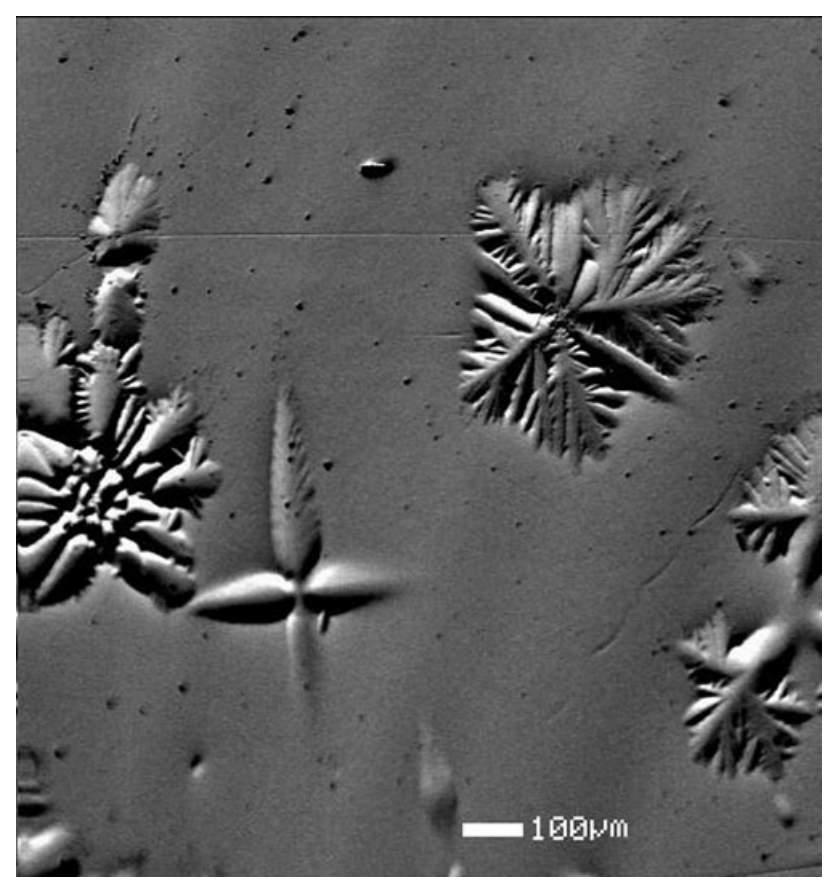

(a)

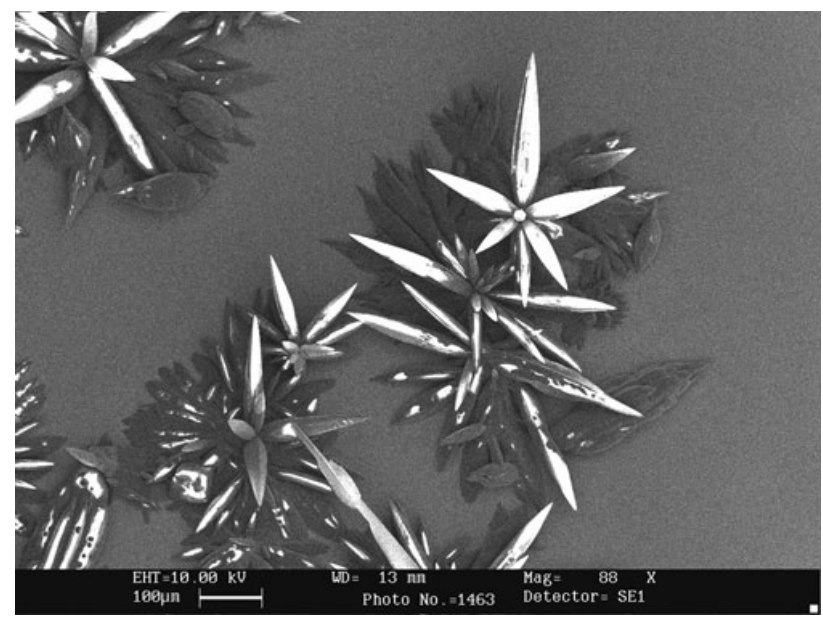

(b)

Figure 2. SEM micrographs of GaSb surface after anodization in HF solution: evidence of (a) electropolishing and (b) galliumoxo-fluoride crystal formation.

The surface of the anodized samples has been studied by SEM. It can be seen that electropolishing takes place during the anodization in HF solution, and it proceeds along preferential directions, while no pore formation can be observed (figure 2(a)). Furthermore, the formation of complex ('flowerlike') structures constituted by rods of different dimensions (hundreds of microns down to hundreds of nanometers) is evident (figure 2(b)). The composition of these structures has been investigated by x-ray microanalysis, and it can be concluded that gallium-oxo-fluoride crystals have grown on the sample surface.

On the other hand, after the electrochemical process in $\mathrm{HCl}$, the formation of a homogeneous dark layer was visible, and SEM investigation revealed the presence of pores. In order to study the pore morphology as a function of the current density, etching in galvanostatic conditions was carried out 


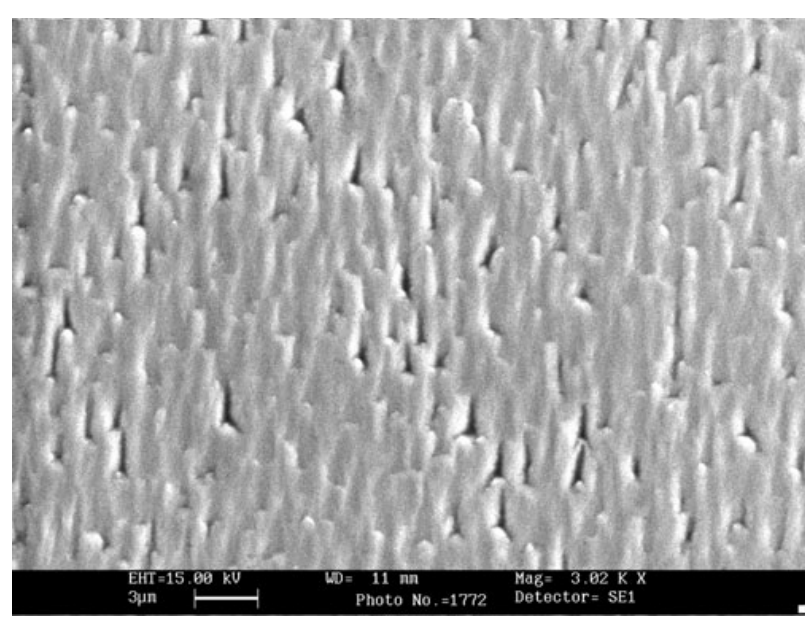

(a)
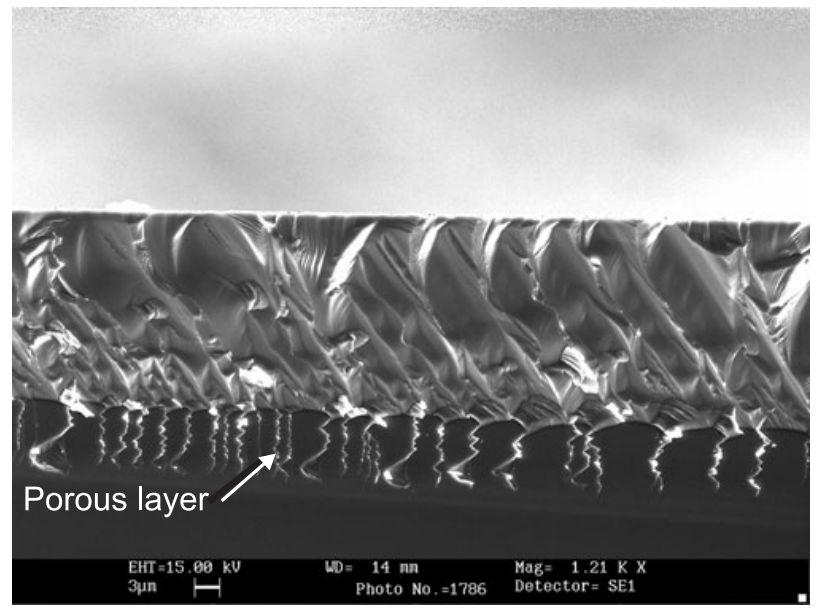

(c)

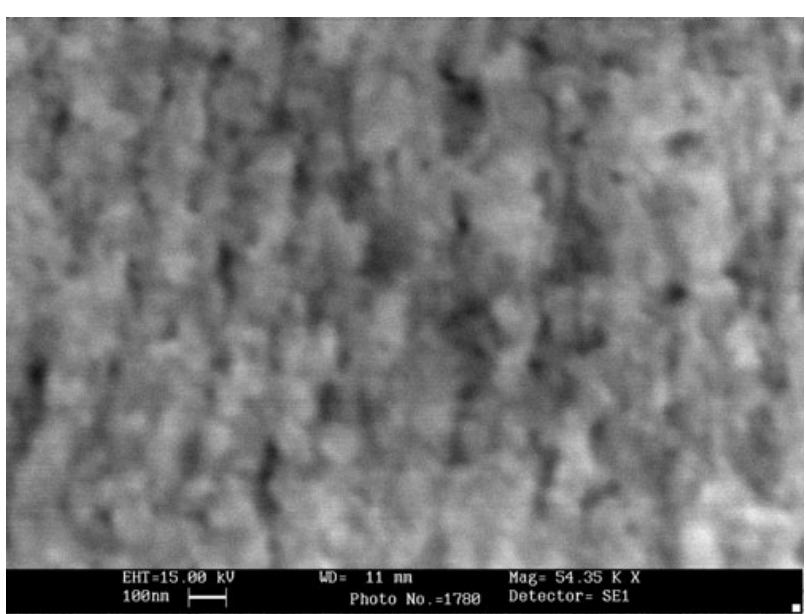

(b)

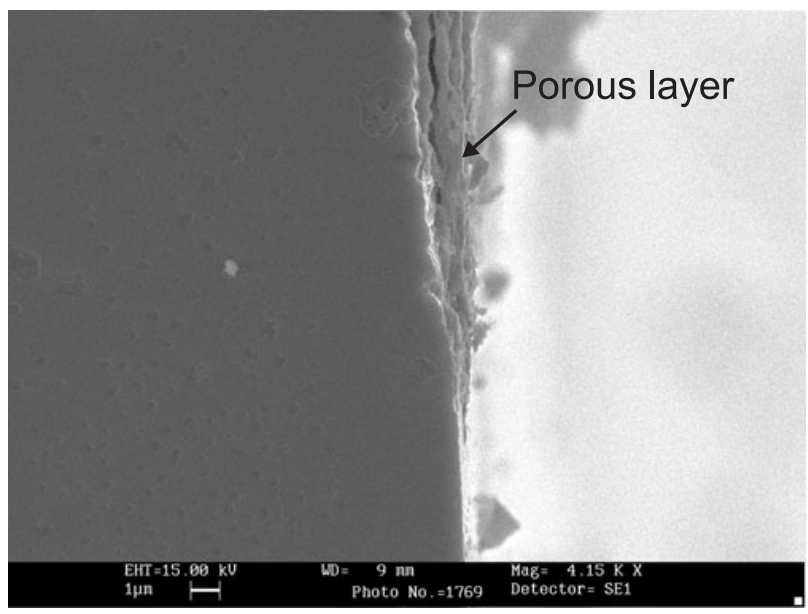

(d)

Figure 3. SEM micrographs of GaSb after galvanostatic etching in $\mathrm{HCl}$ solution: top views $(a),(b)$ and cross sections $(c),(d)$ for anodization at 0.5 and $15 \mathrm{~mA} \mathrm{~cm}^{-2}$, respectively.

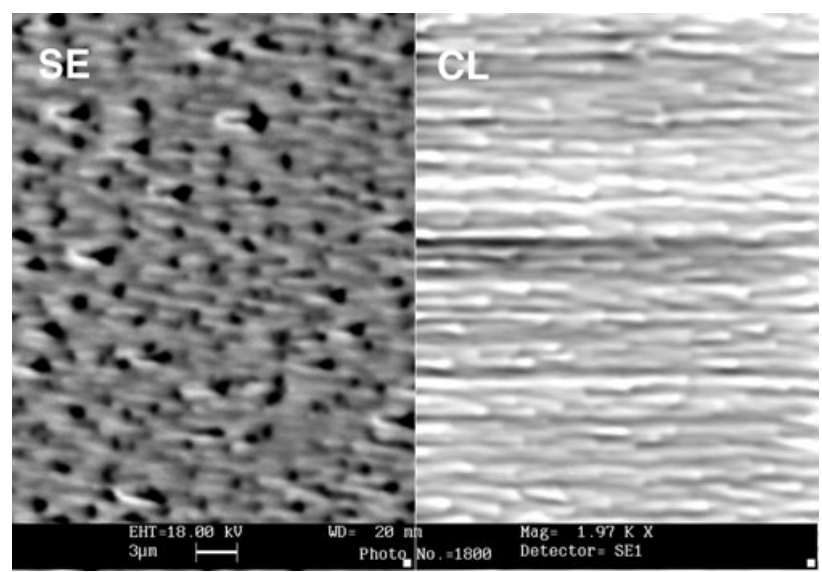

Figure 4. SEM and panchromatic CL images of GaSb anodized at $0.5 \mathrm{~mA} \mathrm{~cm}^{-2}$.

in $\mathrm{HCl}$ electrolyte at two different current values: 0.5 and $15 \mathrm{~mA} \mathrm{~cm}{ }^{-2}$. The anodization time was $480 \mathrm{~s}$ and $300 \mathrm{~s}$, respectively. The top-view and cross-section SEM images of the resulting porous layers are shown in figure 3 . In the case of low current density $\left(0.5 \mathrm{~mA} \mathrm{~cm}^{-2}\right)$, the formation of a

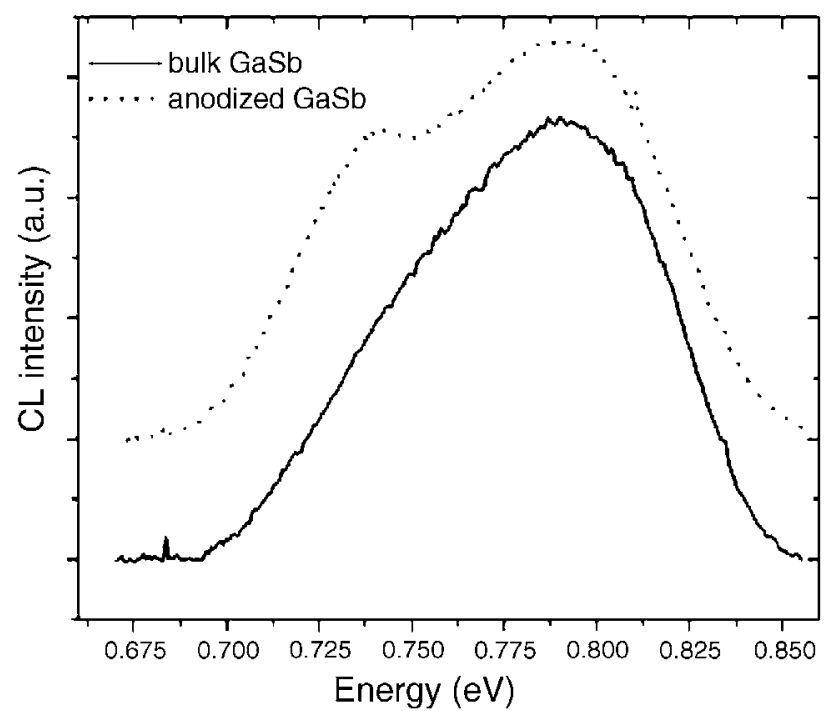

Figure 5. CL spectra of a bulk region (solid line) and anodized area at $0.5 \mathrm{~mA} \mathrm{~cm}^{-2}$ (dotted line).

macroporous layer is evident (figure 3(a)). Micrographs of the cross section (figure 3(c)) show that pores are oriented along 


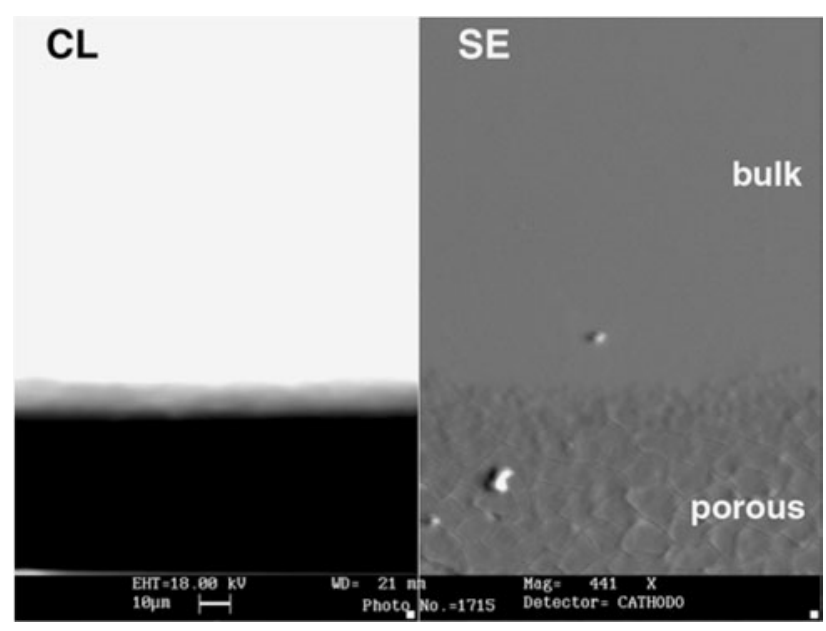

Figure 6. SEM and panchromatic CL images of GaSb anodized at $15 \mathrm{~mA} \mathrm{~cm}^{-2}$.

specific directions, and they do not follow the current flow perpendicular to the sample surface. The anisotropy is clearly visible also in the top view (figure 3(a)), where a triangular shape can be seen. This behaviour has been reported for the electrochemical etching of other III-V compounds, such as InP [13] and GaAs [22], and it has been attributed to the influence of the crystallographic directions on the pore growth. SEM pictures of samples anodized at higher current density $\left(15 \mathrm{~mA} \mathrm{~cm}^{-2}\right)$ show the formation of pores with a completely different morphology (figure $3(b)$ ). In this case, no preferential directions for the pore growth can be observed, and the typical pore size appears to be less than $100 \mathrm{~nm}$.

In order to observe possible modifications of the luminescence properties with respect to the bulk material, the obtained samples were characterized by CL. In the case of low anodization current, panchromatic CL images show that luminescence from the pores is more intense (see figure 4). Comparison of the CL spectra acquired from the anodized area and from the bulk material (figure 5) reveals that no new peaks are observed from the porous material, and in both cases the dominant emission is located at around $0.8 \mathrm{eV}$, which corresponds to the band-band transition [23]. The emission at $0.74 \mathrm{eV}$, which appears better resolved in the porous layer than in the bulk region, is associated with defect complexes involving Te [24].

On the other hand, in the case of the higher current density value, $\mathrm{CL}$ is strongly quenched, as panchromatic CL images show (figure 6). The same behaviour has been observed in the case of porous InP [25]. This may be explained as a consequence of the large specific surface of the porous layers, where electron-hole pairs can efficiently recombine by nonradiative transitions.

\section{Conclusions}

In summary we have shown that anodization of $n-G a S b$ in aqueous $\mathrm{HCl}$ electrolyte leads to the formation of a porous layer. Depending on the current density value, two different morphologies can be obtained: macropores oriented along specific directions are formed at low current density, while pores with dimensions of tens of nanometers and without preferential directions of growth are observed in the case of high current density. CL characterization shows that luminescence is strongly quenched in the material anodized at high current density. Anodization in HF solution has also been investigated: electropolishing and gallium-oxo-fluoride crystals formation have been observed but no porosification has been obtained.

\section{Acknowledgments}

This work is carried out in the framework of a European Marie Curie project (HPMT-CT-2001-00215). Support of MCYT (MAT2003-00455) is acknowledged.

\section{References}

[1] Canham L T 1990 Appl. Phys. Lett. 571046

[2] Canham L T (ed) 1997 Properties of Porous Silicon (London: INSPEC)

[3] Föll H, Langa S, Carstensen J, Christophersen M and Tiginyanu I M 2003 Adv. Mater. 15183

[4] Schmuki P, Fraser J, Vitus C M, Graham M J and Isaacs H 1996 J. Electrochem. Soc. 1433316

[5] Schmuki P, Lockwood D J, Labbé H J and Fraser J W 1996 Appl. Phys. Lett. 691620

[6] Schmuki P, Erickson L E, Lockwood D J, Fraser J W, Champion G and Labbé H J 1998 Appl. Phys. Lett. 721039

[7] Belogorokov A I, Karavanskii V A, Obraztsov A N and Timoshenko V Yu 1994 JETP Lett. 60274

[8] Erne B H, Vanmaekelbergh D and Kelly J J 1996 J. Electrochem. Soc. $\mathbf{1 4 3} 305$

[9] Tjerkstra R W, Rivas J G, Vanmaekelbergh D and Kelly J J 2002 Electrochem. Solid-State Lett. 5 G32

[10] Mynbaeva M, Titkov A, Kryganovskii A, Ratnikov V, Mynbaev K, Huhtinen H, Laiho R and Dmitriev V 2000 Appl. Phys. Lett. 761113

[11] Li X, Kim Y W, Bohn P W and Adesida I 2002 Appl. Phys. Lett. 80980

[12] Ferreira N G, Soltz D, Decker F and Cescato L 1995 J. Electrochem. Soc. 1421348

[13] Langa S, Tiginyanu I M, Carstensen J, Christophersen M and Föll H 2000 Electrochem. Solid-State Lett. 3514

[14] Liu A and Duan C 2001 Appl. Phys. Lett. 7843

[15] Schmuki P, Schlierf U, Herrmann T and Champion G 2003 Electrochim. Acta $\mathbf{4 8} 1301$

[16] Schmuki P, Santinacci L, Lockwood D J and Graham M J 2003 Phys. Status Solidi a 19771

[17] Plugaru R, Cracian G, Nastase N, Méndez B, Cremades A, Piqueras J and Nogales E 2000 J. Porous Mater. 7291

[18] Rams J, Méndez B, Cracianu G, Plugaru R and Piqueras J 1999 Appl. Phys. Lett. 741728

[19] Cullis A G, Canham L T, Williams G M, Smith P W and Dosser O D 1994 J. Appl. Phys. 75493

[20] Denisov V N, Mavrin B N and Karavanskii V A 2002 J. Opt. Technol. 6967

[21] Sabataityté J, Šimikiené I, Baranov A N, Bendorius R A and Pačebutas V 2003 Mater. Sci. Eng. C 2343

[22] Langa S, Carstensen J, Christophersen M, Föll H and Tiginyanu I M 2001 Appl. Phys. Lett. 781074

[23] Méndez B, Dutta P S, Piqueras J and Dieguez E 1995 Appl. Phys. Lett. 672648

[24] Dutta P S, Méndez B, Piqueras J, Dieguez E and Bhat H L 1996 J. Appl. Phys. 801112

[25] Föll H, Carstensen J, Langa S, Christophersen M and Tiginyanu I M 2003 Phys. Status Solidi a 19761 